\title{
RADIATION EXPOSURE BY RADIO-DIAGNOSTICS IN SWITZERLAND: A PILOT PATIENT-ORIENTED SURVEY
}

\author{
A. Aroua ${ }^{1, *}$, J.-F. Valley ${ }^{1}$ and J.-P. Vader $^{2}$ \\ ${ }^{1}$ University Institute of Applied Radiation Physics, Grand-Pré 1, 1007 Lausanne, Switzerland \\ ${ }^{2}$ University Institute of Social and Preventive Medicine, Bugnon 17, 1005 Lausanne, Switzerland
}

\section{Received February 25 2004, accepted April 82004}

\begin{abstract}
A patient-oriented survey was conducted in Switzerland with the aim to establishing the distribution of medical X-ray examinations among the population. A sample of 1235 people aged between 15 and 74 y (589 males and 637 females) was contacted. The participants were asked to give the number of medical X-ray examinations performed during the previous 12 months. Three-fourths of the sample did not undergo any medical X-ray examination during a 12 month-period, and $10 \%$ of the population underwent more than 1 medical X-ray examination in a year. These results were independent of the geographic region. The age distributions of the participants who did not undergo any medical $X$-ray examination and those who underwent one medical X-ray examination were similar. On the other hand, the age distribution of the participants who underwent more than one medical X-ray examination was characterised by a higher contribution from the elderly.
\end{abstract}

\section{INTRODUCTION}

Medical exposure accounts for the largest proportion of artificial irradiation and about one-fourth of the total dose received by the population. Its investigation and control is one of the main tasks in radiation protection. Surveying the exposure of the population resulting from diagnostic and interventional radiology has been performed for the last decades - at national and international levels - a powerful tool for establishing the associated collective detriment ${ }^{(1)}$.

In general, healthcare-provider-oriented surveys of the exposure due to diagnostic and interventional radiology are conducted to evaluate the number of X-ray examinations performed in hospitals and medical practices in order to establish the total collective dose to the population and the average effective dose per caput. But these quantities, very important for radiation protection, do not reveal how the dose is distributed among the population and give no information on the groups of the population who are more exposed than the average.

To date, except the attempt of Maccia et al. ${ }^{(2)}$ to carry out a retrospective assessment of the medical exposure of the population by a phone survey, no study, be it at the national or international level, has collected data that can yield the dose distribution among the population and identify the segment of the population that receives the largest doses (people who undergo a large number of medical X-ray examinations).

Several healthcare-provider-oriented surveys were organised in Switzerland in order to establish the

*Corresponding author: abbas@aroua.com collective dose to the population due to diagnostic and interventional radiology ${ }^{(3-6)}$. The most recent one was carried out in $1998^{(7,8)}$ and indicated that 5.4 M medical X-ray examinations are performed annually in Switzerland, leading to an annual collective dose of $7000 \mathrm{~Sv}$ for a population of 7,096,894. In order to establish how these two figures are distributed among the Swiss population, the report recommended the launching of a patient-oriented survey.

A patient-oriented pilot survey on a stratified sample of the Swiss population was organised in September 2002 aiming at establishing the distribution of medical X-ray examinations among the Swiss population, without reference at this stage to the type of X-ray examination. This paper presents the method, and gives the results of this survey and describes the larger scale study launched in order to establish the distribution of dose due to diagnostic and interventional radiology.

\section{METHODS}

A sample of 1235 inhabitants was contacted, stratified over the five Swiss geographic regions shown in Figure 1: French-speaking Switzerland, Alps and pre-Alps, West Midland, East Midland and the Tessin county. The sample comprises 589 males and 637 females, aged between 15 and 74 y. In a telephone interview, participants were asked to indicate the number of X-ray examinations performed during the last 12 months, excluding dental examinations. The participants were also asked explicitly to ignore ultrasound (US) and magnetic resonance imaging (MRI) procedures. The interviewer described in a simple way these two non-X-ray modalities by explaining that US examinations are performed by 


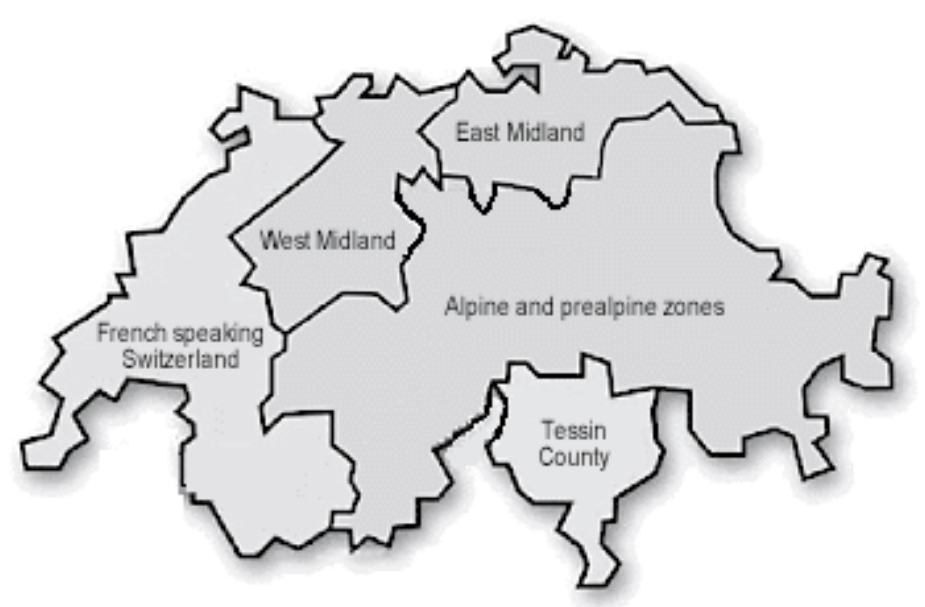

Figure 1. The five Swiss geographic regions used for stratification.

Table 1. Distribution of the participants to the survey with the number of medical X-ray examinations performed per year.

\begin{tabular}{|c|c|c|c|}
\hline $\begin{array}{l}\text { Number of medical X-ray examinations } \\
\text { per caput per annum }\end{array}$ & $\begin{array}{l}\text { Number of } \\
\text { participants }\end{array}$ & $\begin{array}{l}\text { Fraction of the } \\
\text { sample } \%(+2 \mathrm{SD})\end{array}$ & $\begin{array}{l}\text { Associated number of } \\
\text { medical X-ray } \\
\text { examinations }\end{array}$ \\
\hline 0 & 908 & $73.5(+2.5)$ & - \\
\hline$>0 \quad 1$ & 205 & $16.6(+2.1)$ & 205 \\
\hline$>1 \quad 2-5$ & 93 & $7.5(+1.5)$ & 249 \\
\hline $6-10$ & 27 & $2.2(+0.8)$ & 221 \\
\hline $11-15$ & 2 & $0.2(+0.2)$ & 27 \\
\hline Total $>1$ & 122 & $9.9(+1.7)$ & 497 \\
\hline Total $>0$ & 327 & $26.5(+2.5)$ & 702 \\
\hline Total $\geq 0$ & 1235 & 100 & 702 \\
\hline
\end{tabular}

putting a device in contact with the skin and by applying a gel, the example of echography during pregnancy was given. Concerning MRI, the participants were told that during this type of examinations, the imaging unit produces a repetitive noise like a hammer blow.

The carrying out of the pilot survey was entrusted to a Swiss poll agency (Link institute for marketing and social research). This survey was integrated by the subcontractor agency in a much larger survey covering various aspects of life. Therefore, in addition to the data on the age, gender and the number of medical X-ray examinations for a period of $1 \mathrm{y}$, useful for our study, further information on the social and economic status of the surveyed persons, such as household size, working status, level of education, position and household income was also obtained.

The standard formula for estimating the sample population proportion was used to set a $95 \%$ confidence interval for the percentage of persons having undergone at least one radiological examination.

\section{RESULTS AND DISCUSSION}

Table 1 shows the distribution of the surveyed sample with the number of medical X-ray examinations per annum. The survey indicates that over 1235 participants $908(73.5 \%)$ did not have any medical X-ray examination during a period of 12 months. One-quarter $(26.5 \%)$ underwent at least one medical X-ray examination; one-tenth of the participants $(9.9 \%)$ declared that they had more than one medical $\mathrm{X}$-ray examination the previous year.

From the data given in Table 1, the average number of medical X-ray examinations per caput is 0.57 if we consider all the participants. This is to be compared with the figure of 0.76 medical X-ray examination per caput established by the 1998 
nationwide survey ${ }^{(7)}$. The difference between the two figures may be explained by the lack of information in this pilot study on patients above 74 of age, usually performing more examinations than the average. However if we consider only the participants who underwent medical X-ray examinations $(26.5 \%)$, then the average becomes 2.1 medical X-ray examination per caput. A finer estimation would be an average of 1 medical X-ray examination per caput for $16.6 \%$ of the sample, and 4.1 medical X-ray examination per caput for $9.9 \%$ of the sample.

Table 2 and Figure 2 present the age and gender distribution of the participants, ventilated with the number of examinations per annum. The age distributions of the participants who underwent zero X-ray examination (average age of 40.7) and those who underwent one X-ray examination (average age of 41.7) are close to the age distribution of the full sample (average age of 41.1). However, a significant difference in the shape of the age distribution is documented for the categories of participants who underwent more than one X-ray examination: in particular a lower contribution of age categories around 25-34, and a higher contribution of age categories around 55-64. An increase in the average age to 44.4 is observed for the category $2-5 \mathrm{X}$-ray examinations. Above this category, the data suffer from low numbers and are not presented in this study.

Table 2 shows that the category of participants who underwent zero X-ray examination displays almost the same gender distribution as the full sample $(48.4 \% \mathrm{M}, 51.6 \% \mathrm{~F})$. Concerning those participants who underwent one X-ray examination, they show almost the same contribution of males and

Table 2. Average ages and gender distributions for the various categories of participants.

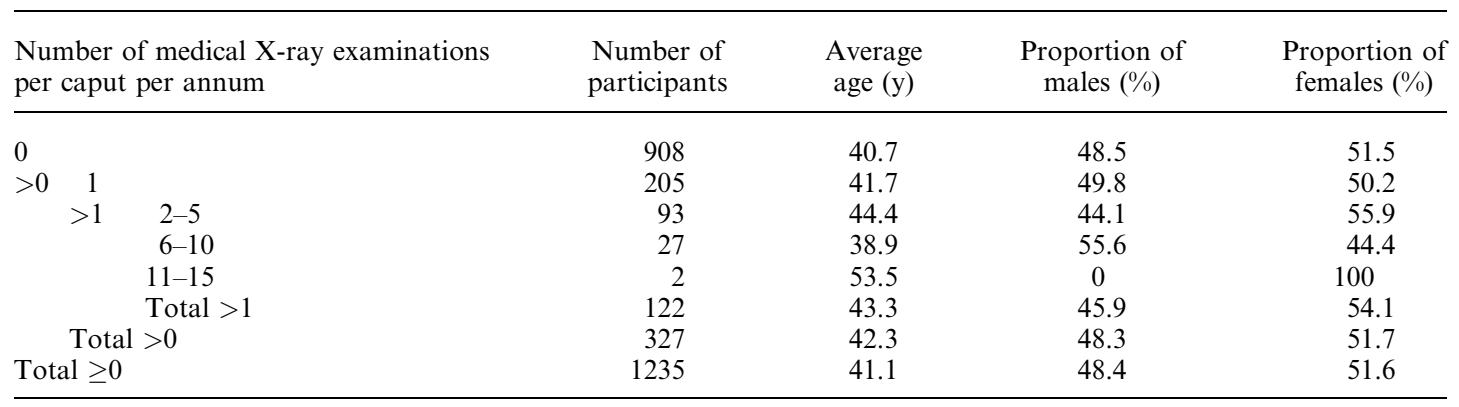

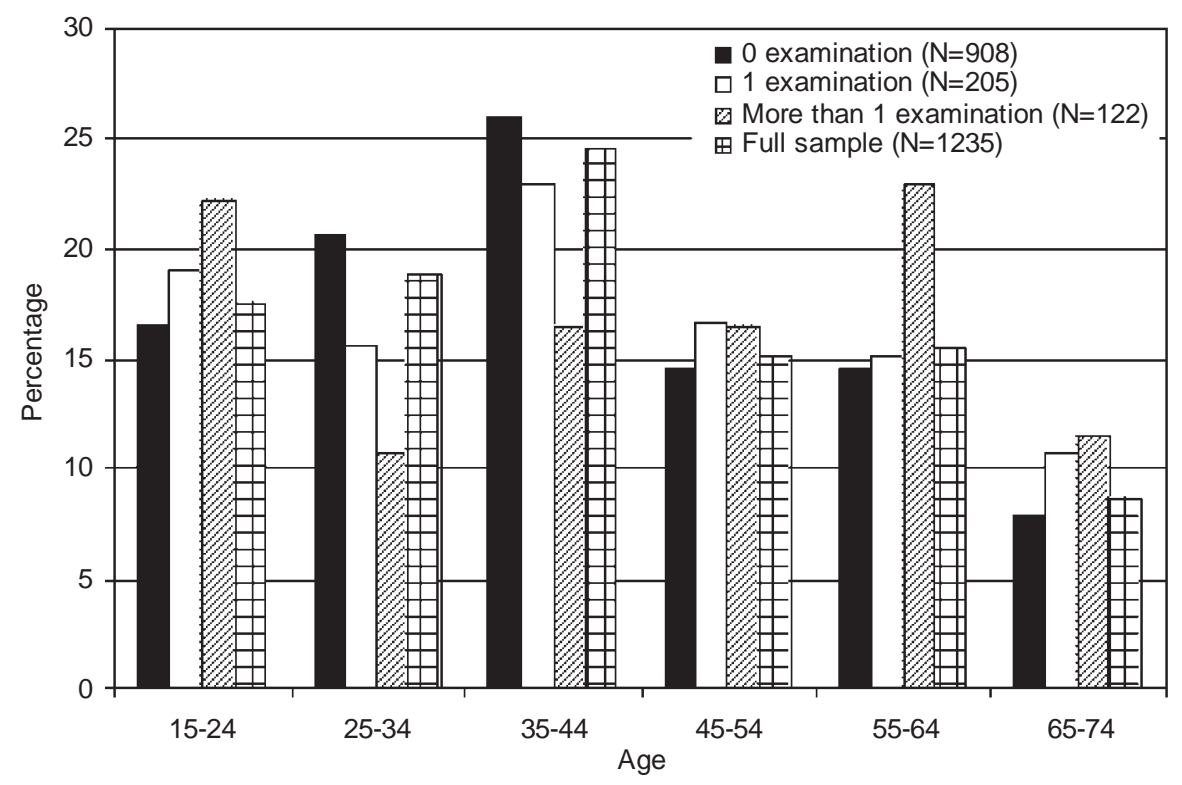

Figure 2. Age distributions. 


\section{A. AROUA ET AL}

females $(49.8 \% \mathrm{M}, 50.2 \% \mathrm{~F})$ whereas for categories of participants who underwent more than one X-ray examination, the results show a slightly higher proportion of females than is the case of the full sample: $(44.1 \% \mathrm{M}, 55.9 \% \mathrm{~F})$ for the category $2-5 \mathrm{X}$-ray examinations.

Figure 3 shows the distribution of the participants with the number of examinations performed for the five main Swiss geographic regions as well as for the urban and the rural areas. These results indicate no significant difference based on these criteria. The slight variations registered in Figure 3 are within the statistical fluctuations.
In the same way, the investigation of socioeconomic factors such as the level of education, the position and the household income indicated no significant difference in the distribution of the participants with the number of examinations performed, based on these criteria.

\section{CONCLUSION}

This pilot study, which covered a sample of 1235 Swiss inhabitants stratified geographically, allowed the establishment of the distribution of medical $\mathrm{X}$-ray examinations among the Swiss population.
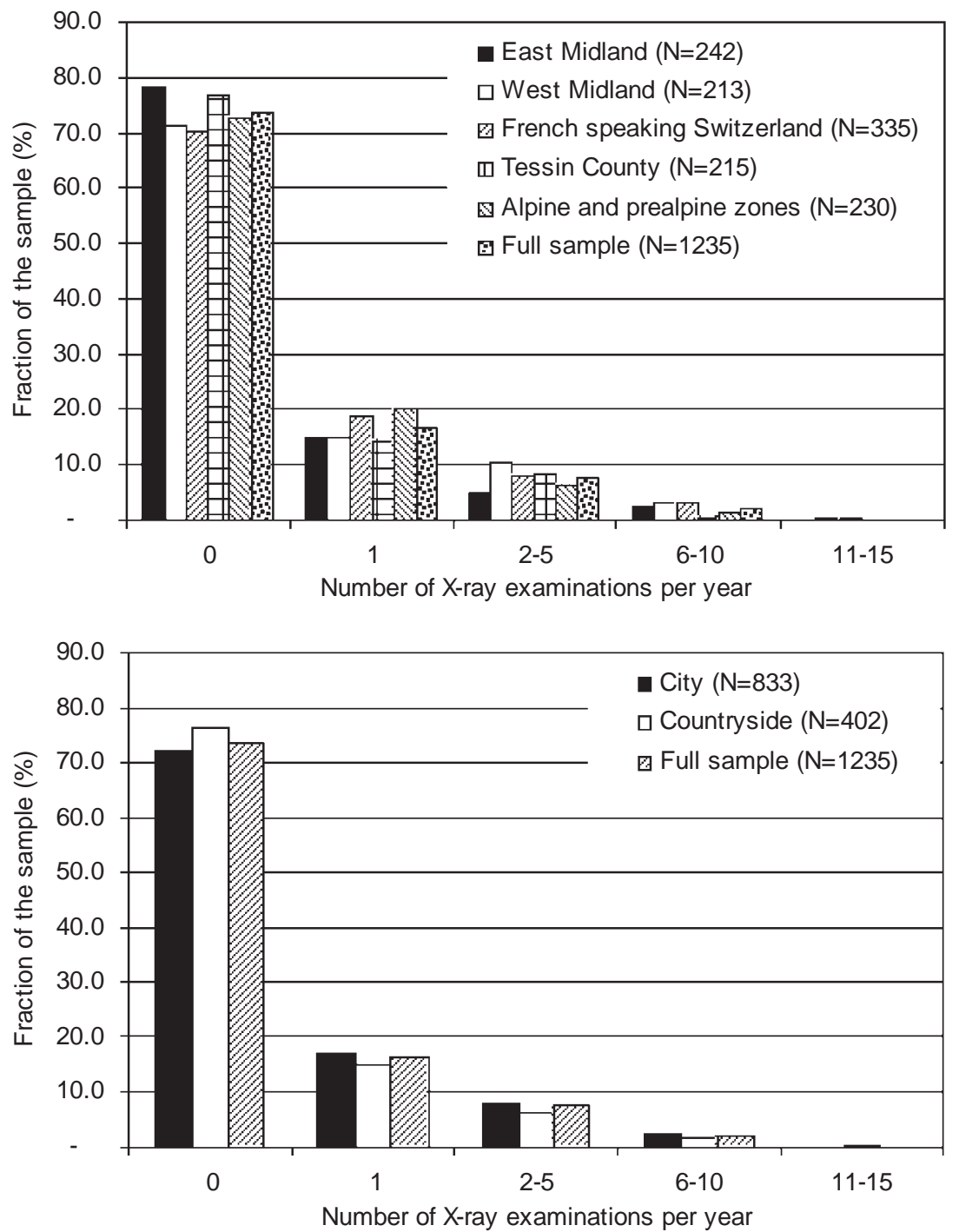

Figure 3. Distribution of the participants with the annual number of medical X-ray examinations, ventilated by the geographic regions, the city and the countryside. 


\section{EXPOSURE BY RADIO-DIAGNOSTICS IN SWITZERLAND}

The results of this survey confirm that the medical X-ray examinations are distributed inhomogeneously and indicate that almost the three-fourths of the population did not undergo any medical X-ray examination during a 12 month period, and that only $\sim 10 \%$ of the population underwent more than one medical X-ray examination a year. This seems to be the case in all geographic regions, in the cities and in the countryside. The results of this study showed that the age distribution is more or less the same for the participants who did not undergo any medical $\mathrm{X}$-ray examination, those who underwent one medical X-ray examination and for the general population represented by the full sample. However, the age distribution of the participants who underwent more than one medical X-ray examination is quite different in shape, and is characterised by a higher contribution of the elderly.

The results obtained in this study are quite helpful for a finer analysis of the results of the 1998 nationwide survey on the exposure of the Swiss population by diagnostic and interventional radiology ${ }^{(7)}$. In fact, the present work suggests that not all the Swiss population is concerned by the $5.4 \mathrm{M}$ medical X-ray examinations registered in 1998, but only about one-quarter which leads to an average of 2.87 medical X-ray examinations per caput per annum within the exposed sub-population, instead of the 0.76 figure based on the total population. Similarly, the collective dose of $7000 \mathrm{~Sv}$ is distributed among $26.5 \%$ of the population only, leading to an average effective dose for this exposed sub-population of $3.7 \mathrm{mSv}$ per caput per annum instead of the $1 \mathrm{mSv}$ per caput per annum based on the total population.

This study does have limits, mainly the noninclusion of children under 15 and the elderly, age 75 and above. The latter group accounts for a significant proportion of the total number of imaging procedures and population dosage. This limitation will be addressed in the full study.

This pilot study was a necessary step in preparation for the launching of the main survey. It gave useful information about the level of the expected statistics. In the main survey, 4000 people will be approached in order to collect information on about 1060 exposed participants and about 1900 medical X-ray examinations. The study will cover not only ages between 15 and 74, but also children
$(<15)$ and the elderly $(>74)$. In addition to the number of X-ray examinations per year, other information useful for dose evaluation will be requested, including the health problem which required the examination, the name of the examination, the part of the body exposed (head and neck, chest, abdomen, upper limbs, lower limbs) and the radiological modality (radiography, fluoroscopy, CT).

\section{ACKNOWLEDGEMENTS}

This research project was funded by the Swiss National Science Foundation (Subsidy No. 3200B0100794).

\section{REFERENCES}

1. United Nations Scientific Committee on the Effects of Atomic Radiation. Sources and effects of ionizing radiation. UNSCEAR 2000 Report to the General Assembly, New York (2000).

2. Maccia, C., Rommens, C., Pagès, P. and Brenot, J. How can a phone survey help in a retrospective assessment of the medical exposure of the population? In: Proceedings of the Tenth Congress of the International Radiation Protection Association, IRPA-10, Hiroshima. (2000).

3. Zuppinger, A., Minder, W., Sarasin, R. and Schär, M. Die Strahlenbelastung der schweizerischen Bevölkerung durch röntgendiagnostische Massnah-men. Radiol. Clin. 30 (1961).

4. Poretti, G., Ionesco, R. and Lanz, W. Erhebung über die Strahlenbelastung der Schweizer Bevölkerung infolge röntgendiagnostischer Untersuchungen, Hrsg., Schweiz. Vereinigung für Atomenergie (1971).

5. Mini, R. and Poretti, G. Die Bestimmung der Strahlenbelastung einer Bevölkerungsgruppe gemäss ICRP26. Tagungsbericht der Schweizerischen Gesellschaft für Strahlenbiologie und Strahlenphysik SGSP (1984).

6. Mini, R.L., Dosisbestimmungen in der medizinischen Röntgendiagnostik. Verlag Max Huber (1992) ISBN 3 906401146.

7. Aroua, A., Buchillier-Decka, I., Vader, J. P. and Valley, J. F. Nation-wide survey on radiation doses in diagnostic and interventional radiology in Switzerland in 1998. Health Phys. 83(1), 46-55 (2002).

8. Aroua, A., Decka, I., Burnand, B., Vader, J.-P. and Valley, J,-F. Dosimetric aspects of a national survey of diagnostic and interventional radiology in Switzerland. Med. Phys. 29(10), 2247-2259 (2002). 